of treatment no material change was made in the administration of the remedies used. The cannabis Indica was employed in increasing doses, till the maximum dose of a fhid drachm was given each four hours. The treatment was continued above four weeks. The case for some ten days seemed shrouded by uncertainty-the horizon cloudy and dismal. A passing breath of air, the familiar face of well loved friends, an unknown voice, any unanticipated affair, was sufficient to determine a spasm and produce not only trismus but opisthotonos.

The patient was discharged at the end of six weeks, apparently cured. Some two months have intervened without witnessing any return of tetanic symptoms.

With regard to the large doses of the cannabis Indica swallowed by the patient, the object was to bring him under its influence. If a smaller amount would have had the desired effect it would not have been increased beyond that. Whenever these doses were given they gave decided relief. The patient frequently begged for the welcome draught. I do not know what might be the result of other remedies, but it does seem to me that a trial of this in every case should be made, if only for the relief of pain it produces.

The diet of the patient was milk and beef tea. He was allowed to driuk of cold water whenerer he desired it.

\section{Selected gepaprs.}

\section{LUXATIONS OF THE HIP-JOINT.}

[VE take the following article from the Chicago Medical Examiner. It speaks for itself.]

Mr. Ediror :-In a pamphlet* which Professor Gunn has somewhat widely distributed in this vicinity, and which has been brought to my notice since I recently returned from abroad, he makes the following remarks :-

"Professor Bigelow does me great injustice in the manner in which he alludes to my writings; on this subject, he says :“" Professor Gunn maintains, in a paper apon this subject, that any untorn or undissected portion of the capsular ligament is capable
shoulder laxations.",

- Luxations of the Hip and Shonlder Joints, and the Agents which oppose their Reduction. By Moses Gnnn, A.M., M.D., Profossor of the Principles and Practice of Surgery and Clinical Surgery in Rush Medical College; formerly Professor of Civil and Military Surgery in the University of Michigan. Second Edition. Chicago, 1869.
This is quoted from a part of my paper intended to do justice to the theories of different writers upon the questions of muscular and capsular resistance in hip dislocation.

I trust that Professor Gunn, for whom I entertain great respect, will acquit me of any intentional act of injustice. The abore statement was made upon a careful study of his pamphlet, which I first met with several years after my own theory was made public. In now re-examining Professor Gunn's pamphlet, I see no reason for modifying the statement to which he objects; indeed, his views differ so widely from mine, in respect to the varieties, classification, pathology, and treatment of hip dislocation, and, in fact, as to everything except the general region of the capsule concerned in two of seven regular dislocations, that his pamphlet does not strictly require a reply.

Professor Gunn confines himself chiefly to the question of resistance to reduction in two dislocations. namely, the dorsal and so-called "ischiatic." It may be observed, however, that, of the two dislocations alluded to, he fails to appreciate the character of what he, in common with previous writers, calls the " ischiatic" luxation, which, in the only case he cites (p. 13), was, as he says, primarily dorsal. If it was primarily dorsal, as alleged, Professor Gunn's remarks really refer, not to two luxations, but only to one, namely, the dorsal ; because, as the tendon of the obturator interuus must have been ruptured, to allow a change of place from the dorsum to the ischiatic notch, the luxation be calls " ischiatic" had no proper claim to be so designated, but was simply dorsal. But the present communication is addressed only to the question of "injustice" to Professor Gunn.

My paper* embraces a general treatise upon hip luxations, of which seven regular varieties are enumerated, four at least being new, and all owing their phenomena, as $I$ believe, chiefly to a single portion of the capsule of the hip, namely, to the iliofemoral or $Y$ ligament (so called for brevity), in one or both of its branches.

Professor Gunn, on the other hand, recognizing only the four luxations of previous writers, urges that in a paper published in 1853, and subsequently incorpo-

- The Mechanism of Dislocation and Fracture of the Hip. With the Reduction of the Dislocations by the Flexion Method. By Henry J. Bigelow, M.D., Professor of Surgery and Clinical Surgery in the Medical School of Harvard University; Surgeon of the Mass. Gon. Hospital, etc. Philadelphia, 1869. 
rated with other papers in a pamphlet which he now republishes, he had already identified the anterior and inferior portion of the capsular ligament as a cause of resistance to reduction in the dorsal luxation, and in the (erroneously so called) ischiatic luxation. But he fails to add, that he similarly identifies, in the same pamphlet, another and different part of the capsule as the cause of the resistance in other luxations.

Again (to return to this point): Professor Gunn states, that, in the "dorsal" and so-called "ischiatic" luxations (after the posterior and upper half of the capsule is cut away), the anterior and inferior half of the capsule binds down the head of the bone, and opposes its reduction (p. 5).

Professor Gunn here speaks only of two similar and allied luxations-probably only of one-and shows no knowledge of the existence of an ilio-femoral ligament. He also points out, as essential, the resistance of the inferior portion of the capsule, adjoining the obturator foramen, where it is actually thinnest and least capable of resistance to reduction. Indeed, he defines very imperfectly even the "half" of the capsule to which he calls attention. In an account of an experiment in the winter of 1858-9, he says (p. 11), that "the upper and posterior half of the capsule was then cut away;" while in reference to other experiments, in 1868-9, he says (p. 18), that "the upper and outer portion of the capsular ligament" was removed, at the same time identifying this as "the dissection used in former experiments."

But I am nevertheless ready to concede, that, within these narrow limits, namely, in designating loosely an anterior capsular resistance in dorsal dislocation, Professor Gunn is in the main correct and deserving of the credit it was my object to accord to him. He goes further, and, as I think, astray.

He directs, that, "in the forward dislocation upon the pubes, while extension and counter-extension is being made in the usual manner" (i. e. by the old method of longitudinal extension), "the limb should be rotated externally ; this," he says, "relaxes the posterior and untorn portion of the ligament" (p. 20).

I think that Professor Gunn will not contend that this posterior portion of the capsular ligament, "untorn," as he says, in the pubic luxation, and therefore to be relaxed by a special position of the limb, is identical with the anterior portion, which he has repeatedly before pointed out as "untorn" in the dorsal luxation, and which is to be relaxed, as he states, by a wholly different position of the limb.

It is plain that two different parts of the capsule are here referred to by Professar Gunn; and, as these two parts manifestly comprehend the whole, these passages alone are sufficient to show that there is no injustice in attributing to him, in the sentence he has quoted, the theory that "any" untorn or undissected portion of the capsular ligament is capable of producing the signs of hip and shoulder luxations.

But in thus refuting the specific charge of Professor Gunn, I have not spoken of the general drift of his whole pamphlet, the couclusions of which are summed up on its lasit page, and which still further substantiate my expressed conviction. His theory for both hip and shoulder is, that, when the bone passes to one side of the socket, it tears that side of the capsule, and leaves the rest sound, and that the essential resistance to reduction is due to this remaining sound side. This theory is indeed the key note of Professor Gunn's paper, and upon it he bases his system of reduction. In the dorsal dislocation, for example, of which it almost exclusively treats, he considers that because the head of the bone is found upon the dorsum it should be reduced through the dorsal laceration, and reiterates (pp. 13, $14,16,18,20)$, even in italics, the necessity of adducting the limb across the other for this purpose. In his only reported case, he accomplishes this (in his own words, " arte non vi"), by a Jarvis's adjuster (p. 13). He says (p. 20), “We further lay down the following special rules:-In the luxation upon the dorsum ilii, the patient lying on his back, carry the limb across its fellow at a point corresponding with the union of the middle with the upper third, rotate inwards, and the pelvis being fixed by an assistant, the head may now be readily drawn into its place." - that is, through the dorsal laceration of the capsule, no matter how inconsiderable this may be. According to my theory,.(lorsal dislocations are best reduced from below the socket, after the capsular orifice is enlarged if it is constricted, with the thigh flexed at right angles to relax the $\mathbf{Y}$ ligament, and sometimes even finally abducted.

"In all dislocations," says Professor Gunn, finally, "place the limb in just the position which characterized it at the moment of escape, and the reduction will then be easily effected" (p. 20), a direction which would prove, as I think, sometimes impracticable and sometimes erroneous. Different 
positions for the different luxations, both of the hip and shoulder, are enumerated in "special" and "general" rules (pp. 1920)-clearly indicating a belief that in different luxations differenl parts of the capsule are torn, and, as a consequence, that different parts of the capsule remain, at once essential to the phenomena, and requiring to be relaxed by wholly different positions, in order to reduce the limb.

My meaning would perhaps have been more exactly rendered by saying, " Professor Gunn maintains, in a paper upon this subject, that different [rather than any] untorn or undissected portions of the capsular ligament are the essential agents of resistance in the reduction of hip and shoulder luxations."

This doctrine is wholly opposed to miy own, which recognizes the $\mathrm{Y}$ ligament as the chief obstacle to reduction, in seven regular dislocations, and directs flexion of the thigh to orercome its resistance.

But upon this point, Professor Gunn, after speaking of the " anterior and inferior portion," or, as he also characterizes it, "half," of the capsular ligament, and its relation to dorsal dislocation, says, "Surely this language includes the so-called $\mathrm{Y}$ liga ment, unless its author finds also a new location for that structure," thus claiming by implication a knowledge of the pathological functions of the $Y$ ligament. Professor Gunn should remember, that, although the greater may, in one sense, include the less, as a block of marble does a statue, yet that there is no sentence or word in his whole pamphlet which alludes to the existence of an ilio-femoral ligament in thecapsule. Inasmuch as this ligament is one of the strongest in the body, "thicker than the ligament of the patella or of the tendo Achillis,"* and is only a part of the literally "undissected" (p. 19) half designated by Professor Gunn as producing the phenomena of dorsal dislocation, it is difficult, in view of this silence, to understand how it could have been in bis mind at the time of writing his pamphlet, or why, in common with all other modern surgical writers and authorities, he should have wholly ignored it in this relation till after my paper was published. $\dagger$

Since the above was written, my attention has been directed to a notice in the Chicago Medical Journal (Oct. 1869, p. 581 ), reiterating, under the term " unfuirness," Professor Gunn's charge of "injustice." The writer says also, "So far as

- Traité d'Ostéologie, etc., S. P. Soemmering and G. \& E. Weber. Paris, 1843. pp. 323-324. we are able to see, this author [Professor Bigelow] has added nothing to Professor Gunn's exposition of the subject, save only this new name of that portion of the capsular ligament-the anterior and inferiorheretofore known as the ilio-femoral, but which he christens as the Y ligament."

This zealous defender of Professor Gunn obviously possesses one alleged qualification of an impartial critic: he has not read the paper he criticizes. His remarks require notice only so far as they relate to the charge of " unfairness," which I think needs no further comment.

Hexry J. Bigelot.

Boston, Hiov. 24, 1869.

† Erratux.-The word "published" was here accidentally substituted, in the printed proof, for made public. By seeming to refer to the printing of $m y$ paper in 1869 instead of its public reading in 1861 (see p. 10 ), it does injustice to certain European observations in 1865-8; and on this account I am unwilling to leave it uncorrected. But this is a separate and here wholly incidental question. As far as the passage relates to Prof. Gunn, I believe it to be strictly correct as it stands. I cannot find that he alludes to the ilio-femoral ligament before Sept. 17 th, 1869.

H. J. B.

\section{Aqeports of attloiral Sorietics.}

OBSTETRICAL SOCIETY OF BOSTON. SECRETARY, DAVID F. LINCOLN, M.D.

Nov. . 13th, 1869.-The Society met at the house of Dr. Arnold, at $7 \frac{1}{2}$ P.M. ; the President, Dr. Buckingham, in the chair.

Dr. LYMaN spoke of the death of Dr. Hooker, on the 6 th inst., and at the conclusion of his remarks suggested that $\mathrm{Dr}$. Wellington should communicate to the family in writing the seutiments of sympathy felt by this Society.

Dr. Wellington spoke of the intimate nature of his acquaintance with Dr. Hooker, and its uniform pleasantness. He said that Dr. Hooker, in forty years, had had eight thousand cases of midwifery. In East Cambridge no one's loss could be more felt than his; he was looked up to as a father; he had literally no enemies. He was 70 years old, and bore his age remarkably welt, going about his daily business until within a few weeks of his death.

Dr. Cotring spoke to the same effect, and desired to second the motion of Dr. Lyman. 